\title{
The growing burden of childhood tuberculosis in Southern Tunisia: temporal trends across two decades: 1995-2016
}

\author{
Houda Ben Ayed ${ }^{1,2}$, Lamia Gargouri3 ${ }^{3}$, Makram Koubaa ${ }^{2,4}$, Khaoula Rekik ${ }^{2,4}$, Fatma Hammemi ${ }^{2,4}$, Maissa Ben Jemaa ${ }^{1,2}$
} Mariem Ben Hmida1,2, Abdelmajid Mahfoudh³, Jamel Damak¹, Mounir Ben Jemaa ${ }^{2,4}$

\begin{abstract}
Background: In recent years, childhood tuberculosis (TB) has attracted global interest after a long period of neglect. We aimed to give an update about the epidemiological profile of childhood TB in south of Tunisia and to describe their chronological trends from 1995 to 2016.

Methods: We retrospectively collected data of TB new cases in children aged $<15$ years between 1995 and 2016 in Southern Tunisia. Joinpoint Regression Analysis was performed to analyze chronological trends and annual percentage changes (APC) were estimated.

Results: Overall, 204 cases of TB were noted in children. The average incidence rate of overall TB was 4.09/100000 population/year. There was a significant rise in extrapulmonary tuberculosis (EPTB) incidence (APC $=2.76 \% ; 95 \%$ confidence interval $(95 \% \mathrm{Cl})=[0.40-5.00])$, while pulmonary tuberculosis PTB incidence rate showed a non-significant decrease over time. The under-fives had a significant growing trend (APC of 3.95\%; $95 \%$ $\mathrm{Cl}=[0.80-7.30]$ ). We noted a significant upward trend of TB incidence in rural districts (APC $=4.91 \% ; 95 \% \mathrm{Cl}=[1.90-8.10]$ ). Trends analysis by anatomical site indicated an increase in lymph node TB new cases (APC $=5.26 \% ; 95 \% \mathrm{Cl}=[2.80-7.80]$ ).

Conclusions: A significant rise in TB incidence rate was observed in TB cases, EPTB, notably lymph node, the under-fives and rural districts inhabitants. An increased focus on groups at high risk and implementing preventive strategies in this highly vulnerable population is warranted.
\end{abstract}

Keywords: children, epidemiology, extrapulmonary, pulmonary, tuberculosis

\section{INTRODUCTION}

Tuberculosis (TB) is increasingly becoming a significant cause of morbidity, mortality and health care expenditure all over the world. The World Health Organization (WHO) estimates that globally in 2016, there were 10.4 million incident cases of TB (1). For the past 5 years, it has been the leading cause of death from a single infectious agent, ranking above HIV/AIDS (1). A total of 1.4 million of the global burden of TB cases (10\%) are thought to occur in children (aged $<15$ years). In recent years, childhood TB has attracted global interest after a long period of neglect.

Managing TB in children, a vulnerable population where diagnosis and treatment are not well understood, is potentially challenging, especially in countries with limited public health resources. In light of the lack of a standard case definition, the wide spectrum of disease, the difficulty of obtaining adequate specimens and the low rate of bacteriologic confirmation, the exact extent of childhood TB is still unknown (2). The burden of childhood TB, specifically, is of particular importance as it is a marker of the overall trend of disease and an important indicator of ongoing transmission within the community. Surveillance data on trends in childhood TB in Tunisia, a limited resources country, are scarce in the published literature. The highest rates of TB were recorded in Southern Tunisia, where tuberculosis management is still challenging. This lack of knowledge could contribute to a poor control of TB among children, limiting advances to attain the "End TB" objectives (3).

The understanding of the global epidemiology of childhood TB and the availability of relevant and high-quality surveillance data could be of utmost importance in planning effective control measures.

\footnotetext{
Community Health and Epidemiology Department, Hedi Chaker University Hospital, University of Sfax, Tunisia.

2 Extra-pulmonary Research Unit, Hedi Chaker University Hospital, Sfax, Tunisia.

3 Pediatric Department, Hedi Chaker University Hospital, University of Sfax, Tunisia.

4 Infectious Diseases Department, Hedi Chaker University Hospital, University of Sfax, Tunisia.
}

Correspondence: Houda Ben Ayed, MD

Community Health and Epidemiology Department, Hedi Chaker University Hospital, University of Sfax, Sfax 3029, Tunisia.

E-mail:drhoudabayed@gmail.com

Received: 11 Apr 2019, Accepted: 21 May 2019

(C) 2019 by the authors; licensee Modestum Ltd., UK. This article is an open access article distributed under the terms and conditions of the Creative Commons Attribution License (http://creativecommons.org/licenses/by/4.0/). 
Knowledge about chronological trends in childhood TB incidence can be invaluable to evaluate programs, assess health specific needs and manage the disease. Moreover, taking into account the projected trends of TB in describing their trajectories in future allows the prediction of short-term future incidence rates and the suitable planning of control strategies. In this perspective, our study aimed to give an update about the epidemiological profile of childhood TB in south of Tunisia and to describe their chronological trends from 1995 to 2016.

\section{MATERIALS AND METHODS}

\section{Study Design}

We carried an ecological study of all notified TB cases by the Center of Tuberculosis Control (CTC), from January, 1st 1995 to December, 31st, 2016 in the region of Sfax, South of Tunisia. The governorate of Sfax is situated in the coastal region of Southern Tunisia. In 2014, the general population was 955421 inhabitants, or $8.7 \%$ of the total Tunisian population. The number of children in the governorate of Sfax was 244916 , which represented $25.6 \%$. This region is highly endemic in tuberculosis and hosted a large proportion of rural areas inhabitants searching for job opportunities. In Southern Tunisian rural zones, people suffer from poor housing, low socioeconomical status and lack of access to health care structures. In our country, the notification of TB is mandatory. The CTC affiliated to the corresponding regional health-care directorate received notified cases from both private and public health institutions, coordinated by the National Tuberculosis Surveillance Program.

\section{Inclusion Criteria and Data Collection}

We collected data from the TB regional registries of the CTC during the study period. All children aged under 15 years with diagnosed TB of any site were enrolled in the analysis. Only children who were resident of Sfax Governorate were included. At enrollment, relapsing patients were excluded in order to calculate the incidence rates. We excluded all cases with missing data, which represented less than $3 \%$ in our study. We considered in our analysis only confirmed incident cases of TB. The diagnosis of TB was made by expert physicians who confirmed the diagnosis, established the antituberculous treatment and addressed the notified case to the CTC for additional medical care. The diagnosis was based on the national TB Guidelines, which were consistent with the WHO diagnostic criteria (4). TB was confirmed when Mycobacterium species were isolated from any site of the body. In default, the diagnosis was done based on histological findings, epidemiological, clinical, radiological and histological arguments consistent with TB, or when an adequate response to anti-tuberculosis medication was observed. For analysis, we included exhaustive data on demographics, delegation and full address of TB patients and the site of tuberculosis. Data dealing with the treatment regimen and the disease evolution were also recorded for each patient.

\section{Tuberculosis Incidence Rates}

For practical reasons, we divided eligible children according to the National Population Census: 0-4 years, 5-9 years and 10-14 years. The yearly incidence rate of TB was computed by dividing the total incident TB cases by the average population census, which was calculated as follow: (Sfax population in $2004+$ Sfax population in 2014)/2 based on Tunisian National Institute of Statistics data. The incidence rate was calculated in the three age groups and in both genders and was expressed as the number per 100000 inhabitants/year $(5,6)$.

\section{Statistical Analysis}

Statistical analysis was performed using SPSS.20 software. The Kolmogorov-Smirnov test was used to assess the distribution of quantitative variables. The results of quantitative variables were presented as means \pm standard deviation (SD) or medians and interquartile range (IQR). Those of categorical variables were presented as numbers and percentages. We used the T test for independent samples to compare two means and Anova test to compare several means. For categorical variables, we used the Chi-square test in independent samples.

\section{Current Chronological Trends and Projected Incidence Rates}

We analyzed trends in TB incidence performing Joinpoint Regression Analysis program, version 4.5.1.0. This software is one of the most applicable in piecewise regression which is used for estimation of regression variables and drawing diagrams of fitted regression lines. Joinpoint fits a linear regression model to the data to identify inflexion points ('joinpoints'), using a series of permutation tests, with Bonferroni adjustment for multiple comparisons. A significance level of 0.05 was used for the permutation test, which determines the minimum number of "joinpoints" necessary to fit 
Table 1: Distribution of basic demographics, clinical and therapeutic characteristics of children with tuberculosis by age groups

\begin{tabular}{|c|c|c|c|c|c|}
\hline \multirow[t]{2}{*}{ Variables } & \multirow{2}{*}{$\begin{array}{l}\text { Total } \\
\mathrm{N}=204\end{array}$} & \multicolumn{3}{|c|}{ Age groups (years) } & \multirow[t]{2}{*}{$\mathbf{p}$} \\
\hline & & $<5(\mathrm{~N}=37 ; 18.1 \%)$ & $5-9(N=64 ; 31.3)$ & $10-14(\mathrm{~N}=103 ; 50.6 \%)$ & \\
\hline \multicolumn{6}{|l|}{ Gender $(\mathrm{N}, \%)$} \\
\hline Males & $107(52.5)$ & $25(67.7)$ & $34(53.1)$ & $48(46.6)$ & 0.09 \\
\hline \multicolumn{6}{|l|}{ Habitancy $(\mathrm{N}, \%)$} \\
\hline Rural districts & $90(44.1)$ & $17(45.9)$ & $24(37.5)$ & $49(47.6)$ & 0.4 \\
\hline \multicolumn{6}{|l|}{ Type of TB } \\
\hline PTB & $37(18.1)$ & $8(21.6)$ & $8(12.5)$ & $21(20.4)$ & \multirow{2}{*}{0.3} \\
\hline EPTB (N,\%) & $167(81.9)$ & $29(78.4)$ & $56(87.5)$ & $82(79.6)$ & \\
\hline Lymph node & $105(62.8)$ & $14(37.8)$ & $42(65.6)$ & $49(47.6)$ & 0.014 \\
\hline Abdominal & $20(12)$ & $3(8.1)$ & $6(9.4)$ & $11(10.7)$ & 0.9 \\
\hline Pleural & $10(6)$ & $3(8.1)$ & $0(0)$ & $7(6.8)$ & 0.08 \\
\hline Bone and joints & $9(5.4)$ & $4(10.8)$ & $2(3.1)$ & $3(2.9)$ & 0.1 \\
\hline Urogenital & $8(4.8)$ & $3(8.1)$ & $2(3.1)$ & $3(2.9)$ & 0.35 \\
\hline Neuro-meningeal & $7(4.2)$ & $0(0)$ & $2(3.1)$ & $5(4.9)$ & 0.37 \\
\hline \multicolumn{6}{|l|}{ Treatment regimen $(\mathrm{N}, \%)$} \\
\hline Fixed dose combination & $55(28.5)$ & $10(31.3)$ & $17(27.9)$ & $28(28)$ & 0.9 \\
\hline Treatment duration (Mean, SD) (months) & $8.9 \pm 5.3$ & $7.23 \pm 2$ & $8.7 \pm 3.9$ & $9.6 \pm 3.9$ & 0.2 \\
\hline \multicolumn{6}{|l|}{ Disease evolution $(\mathrm{N}, \%)$} \\
\hline Favorable & $194(95.1)$ & $36(97.3)$ & $59(92.2)$ & $99(96.1)$ & 0.4 \\
\hline Relapse & $1(0.5)$ & $0(0)$ & $1(1.6)$ & $0(0)$ & 0.8 \\
\hline Death & $3(1.5)$ & $1(2.7)$ & $0(0)$ & $2(1.9)$ & 0.08 \\
\hline
\end{tabular}

N: Number; TB: Tuberculosis; PTB: Pulmonary tuberculosis; EPTB: Extra-pulmonary tuberculosis; SD: Standard deviation

the data. The annual percent change (APC) within each segment was calculated with $95 \%$ confidence intervals $(95 \% \mathrm{Cl})$ (7). Variation in trends of TB incidence for different age groups, for both genders and for TB sites was assessed over time. A p-value less than 0.05 was considered statistically significant.

\section{RESULTS}

\section{Patients' Characteristics}

From 1995 to 2016, 204 cases of TB were noted in children, representing 7.36\% of the total case load for that period. Of all eligible children, 107 cases were males (52.5\%), with a sex ratio of 1.1. The mean age of all children was $8.9 \pm 4.4$ years. The distribution by age groups showed that the largest age group of children was that 10-14 years (103 cases; $50.6 \%$ ), followed by 5-9 years (31.3\%). According to habitancy, 90 cases (44.1\%) lived in rural districts, with no significant difference between the three age groups. Most of TB children had extrapulmonary tuberculosis (EPTB) (167 cases, 81.9\%). Of these, the main EPTB involved site was lymph node in 105 cases (62.8\%), which was significantly more frequent in 59 -year group $(p=0.014)$. Abdominal disease was the second most common reported site of infection, accounting for $12 \%$. The mean treatment duration was $8.9 \pm 5.3$ months. The fixed-dose combination regimen was administered in 55 cases (28.5\%). The disease evolution was favorable in 194 cases (95.1\%) (Table 1).

\section{Average Annual Number and Incidence Rates of Gender and Age-specific TB Cases}

Over a 22-year-study period, the absolute annual number of overall TB in children was 9.25 cases/year. The corresponding average incidence rate was 4.09/100 000 population/year, ranging from 4.86 in 1995 to 6.63 per 100000 population in 2016. The incidence rate of EPTB (3.35/100000 population/year) was higher than pulmonary tuberculosis (PTB) (0.74/100 000 population/year). TB-gender-specific rates showed that incidence rates of EPTB and PTB were 3.68 and $0.46 / 100000$ population/year for males and 2.58 and 1.04/100 000 population/year for females, respectively. Looking at the notification rate by age groups, the highest incidence rate was observed in 10-15-year age-group, with an incidence of $6.23 / 100000$ population/year for overall TB cases. The same findings were applied to EPTB and PTB, with respective incidence rates of 4.96 and 1.25/100 000 inhabitants/year in this age group (Table 2). 
Table 2: Average annual number and incidence rates of gender and age-specific tuberculosis cases overall and by tuberculosis type

\begin{tabular}{|c|c|c|c|}
\hline Tuberculosis & Overall tuberculosis cases & EPTB & PTB \\
\hline \multicolumn{4}{|l|}{ Total } \\
\hline Average population & 226114 & 226114 & 226114 \\
\hline Total number over 22 years & 204 & 167 & 37 \\
\hline Average annual number & 9.27 & 7.59 & 1.68 \\
\hline Incidence rate* & 4.09 & 3.35 & 0.74 \\
\hline \multicolumn{4}{|l|}{ Age groups } \\
\hline \multicolumn{4}{|l|}{$<5$ years } \\
\hline Average population & 78323 & 78323 & 78323 \\
\hline Total number over 22 years & 37 & 29 & 8 \\
\hline Average annual number & 1.67 & 1.31 & 0.36 \\
\hline Incidence rate * & 2.13 & 1.68 & 0.46 \\
\hline \multicolumn{4}{|l|}{ [5-10[ years } \\
\hline Average population & 72689 & 72689 & 72689 \\
\hline Total number over 22 years & 64 & 56 & 8 \\
\hline Average annual number & 2.91 & 2.54 & 0.36 \\
\hline Incidence rate * & 4 & 3.5 & 0.50 \\
\hline \multicolumn{4}{|l|}{$[10-15[$ years } \\
\hline Average population & 75102 & 75102 & 75102 \\
\hline Total number over 22 years & 103 & 82 & 21 \\
\hline Average annual number & 4.68 & 3.7 & 0.94 \\
\hline Incidence rate * & 6.23 & 4.96 & 1.25 \\
\hline \multicolumn{4}{|l|}{ Gender } \\
\hline \multicolumn{4}{|l|}{ Males } \\
\hline Average population & 117255 & 117255 & 117255 \\
\hline Total number over 22 years & 107 & 95 & 12 \\
\hline Average annual number & 4.86 & 4.31 & 0.54 \\
\hline Incidence rate * & 4.14 & 3.68 & 0.46 \\
\hline \multicolumn{4}{|l|}{ Females } \\
\hline Average population & 108859 & 108859 & 108859 \\
\hline Total number over 22 years & 97 & 62 & 25 \\
\hline Average annual number & 4.4 & 2.82 & 1.13 \\
\hline Incidence rate * & 4.05 & 2.58 & 1.04 \\
\hline
\end{tabular}

*(/100 000 population/year); PTB : Pulmonary tuberculosis; EPTB: Extra-pulmonary tuberculosis

\section{Chronological Trends of Tuberculosis in Children by Gender, Age Groups, Habitancy and Main Sites}

Trends analysis performing Joinpoint regression showed a significant increase in the overall TB incidence rate from 1995 to 2016 , with an APC of $2.40 \%(95 \% \mathrm{Cl}=[0.10-4.70])$. The temporal trends for annual EPTB incidence rate showed a significant rise from 4.42/100 000 population in 1995 to 5.31/100 000 population in 2016, with an APC of $2.80 \%$ $(95 \mathrm{Cl} \%=[0.40-5.00])$ in the study area, while PTB incidence rate showed a non-significant decrease over time (APC $=-$ $0.8 \% ; 95 \mathrm{Cl} \%=[-4.60-3.20]$ ) (Figure 1). 
Multiple Joinpoint Models

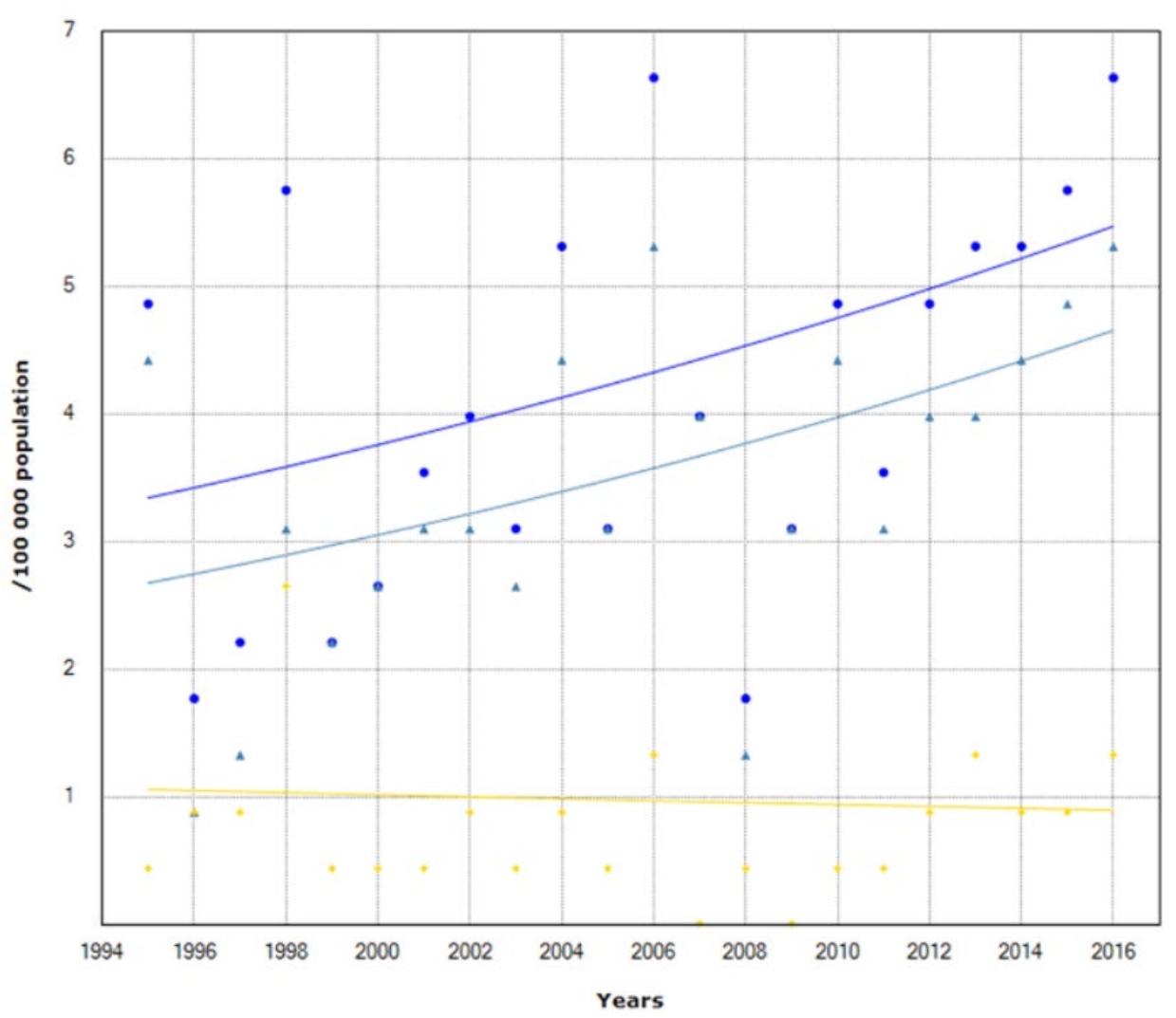

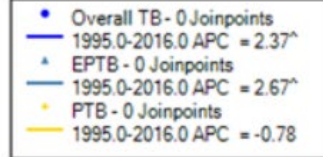

1995.0-2016.0 APC $=-0.78$

Figure 1: Chronological trends analysis of global childhood tuberculosis (TB), pulmonary tuberculosis (PTB) and extrapulmonary tuberculosis (EPTB) incidence rates between 1995 and 2016

Multiple Joinpoint Models

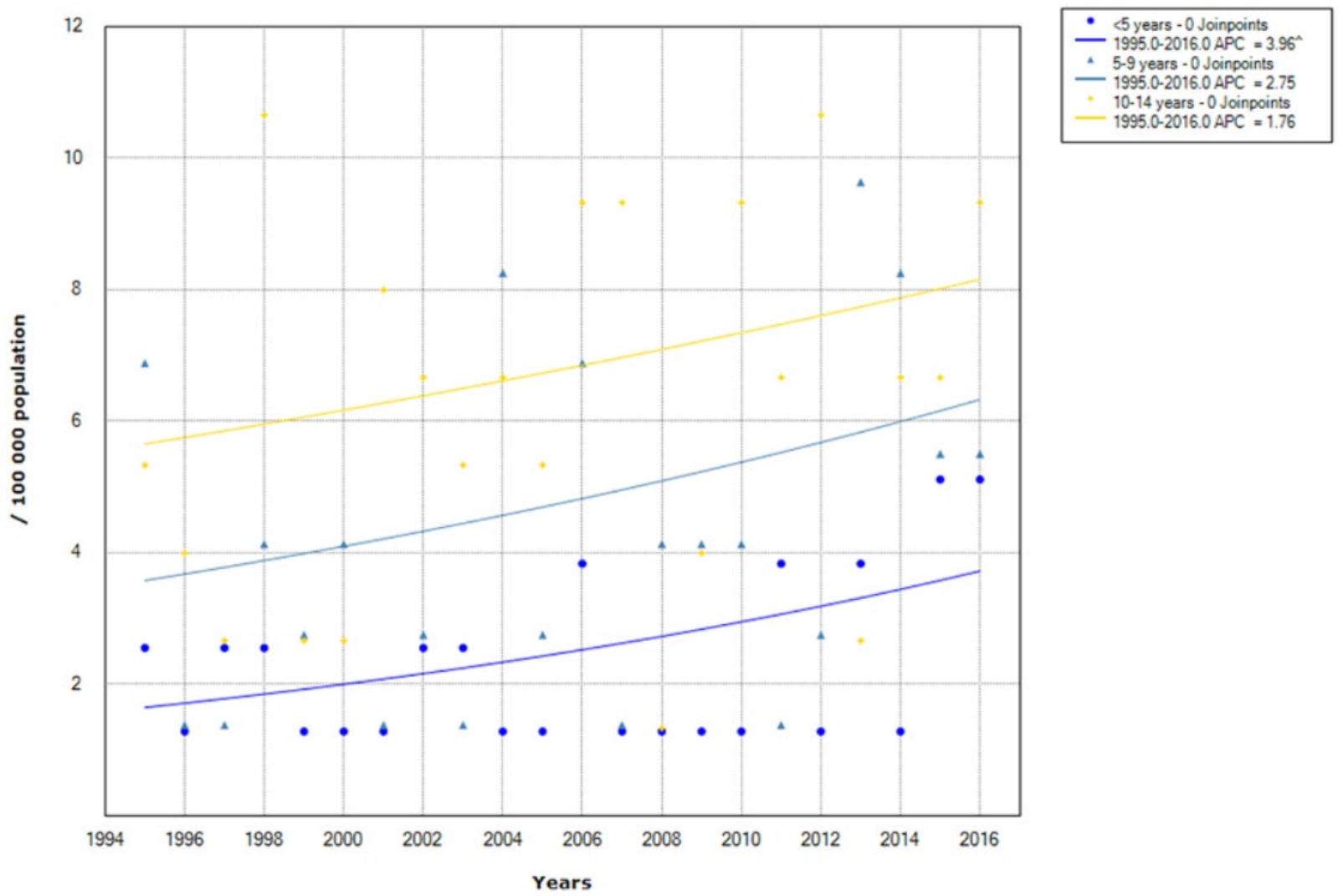

Figure 2: Chronological trends analysis of global tuberculosis incidence rates by age groups between 1995 and 2016 
Multiple Joinpoint Models
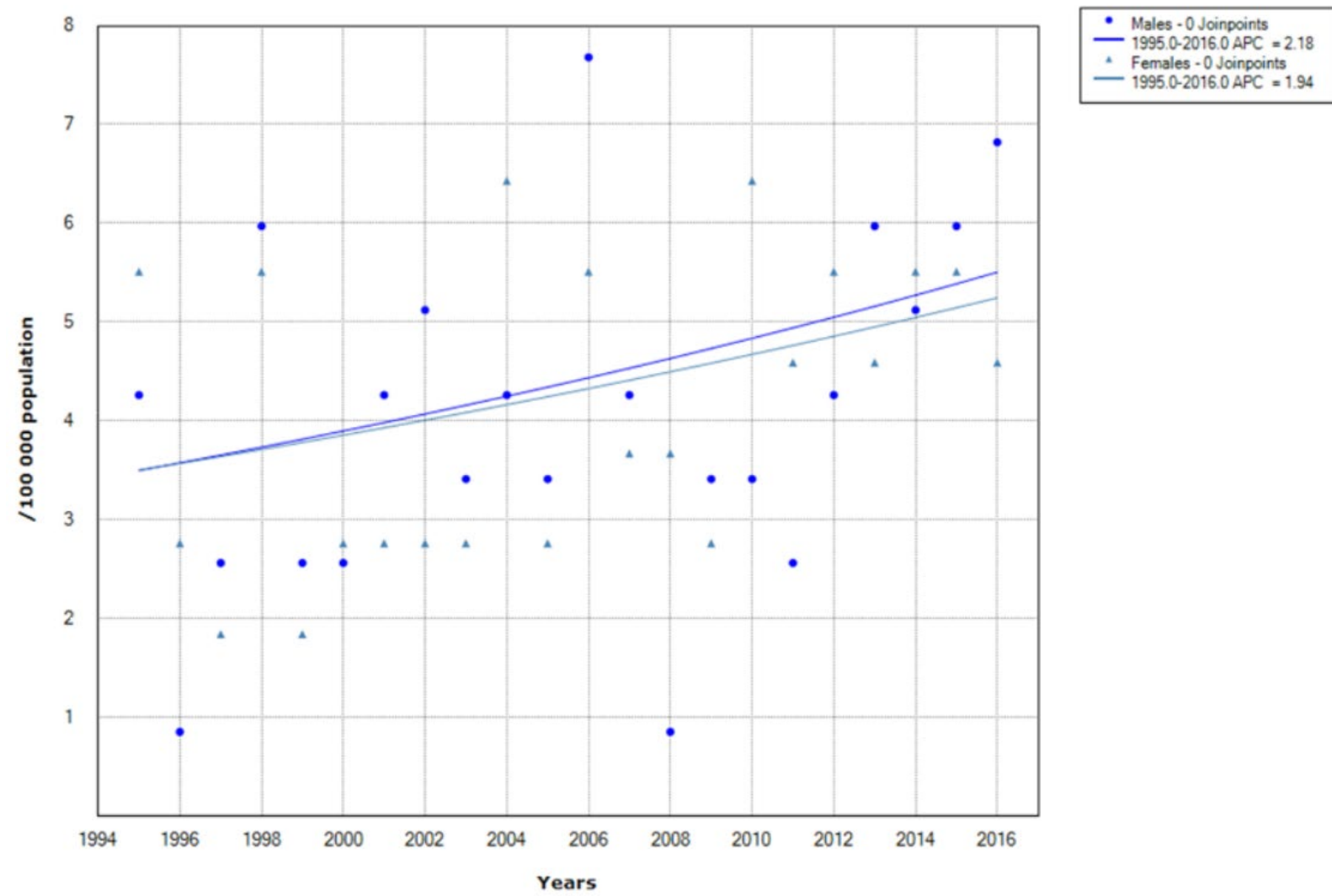

Figure 3: Chronological trends analysis of global tuberculosis incidence rates by gender between 1995 and 2016

Trends analysis of TB-gender-specific rates showed that overall TB incidence increased for males (APC $=2.20 \%$; $95 \% \mathrm{Cl}=[-0.50-5.00])$ between 1995 and 2016, but no significant variation was observed over time. Similar pattern was observed among females (APC $=1.90 \% ; 95 \mathrm{Cl} \%=[0.40-4.40]$ ) (Figure 3). According to age groups, children aged under 5 years had a significant growing trend, with an overall TB incidence rate rising from 2.55/100 000 population in 1995 to $5.11 / 100000$ population in 2016 , with an APC of $3.90 \%(95 \% \mathrm{Cl}=[0.80-7.30])$. As to $5-9$ year and $10-14$-age groups, there was no significant variation during the same period, with respective APC of $2.70 \%(95 \% \mathrm{Cl}=[-1-60.7 .00]$ and $1.80 \%(95 \%$ $\mathrm{Cl}=[-1 \cdot 30-4.90])$. 
Multiple Joinpoint Models

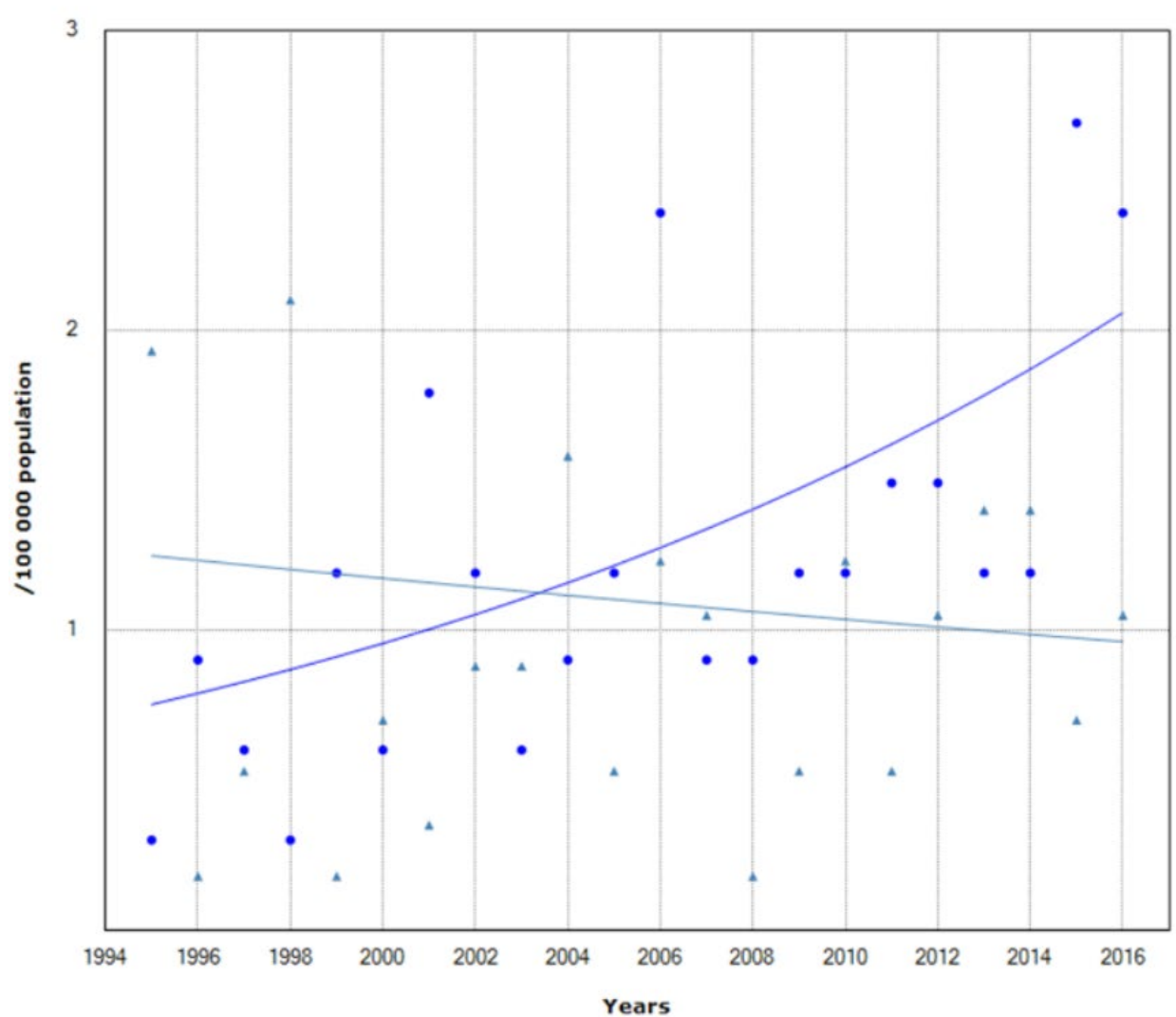


Over the study period, there was a significant upward trend of TB incidence in rural districts, from 0.30/100 000 inhabitants in 1995 to 2.39/100 000 inhabitants in 2016, with an APC of $4.90 \%(95 \% \mathrm{Cl}=[1.90-8.10])$. In urban district, a decreasing trend was noted, but with no significant change (APC $=-1.20 \% ; 95 \% \mathrm{Cl}=[-4.80-2.40]$ ). When stratified by TB site, the annual number of TB indicated a significant rise in lymph node tuberculosis, from 4 to 8 new cases (APC $=5.30 \%$; $95 \% \mathrm{Cl}=[2.80-7.80])$.

\section{DISCUSSION}

Our study provided original, comprehensive and recent data on the epidemiological features and clinical characteristics of childhood TB in South of Tunisia. It showed that the TB burden in Tunisia remains high among children aged under 15 years and continues to pose a serious public health challenge. In spite of the implementation of effective National TB Control Program, significant rise in TB incidence rate was observed in overall TB cases, EPTB, notably lymph node, the under-fives and children living in rural districts. These findings represented failure to control transmission in the society and contributes significantly to the burden of disease as a reservoir. The policy of BCG vaccination at birth should therefore be continued, and screening of children on school entry and on return from vacation would be useful for an early case identification.

Pediatric cases of TB accounted for nearly $7 \%$ of the total TB case load. Other similar proportions were reported, ranging from 5 to $7 \%$ in Australia, Netherlands and the USA (8-10) and from 7 to $8 \%$ in Denmark (11). We noted that 10 to 14 years cases contributed to approximately one-half of the total childhood TB, suggesting that tuberculosis in our pediatric population is a disease that favors the ages 5 to 14 years. Previous studies reported that 5-14-year and 13-17 year-groups accounted for $61.7 \%$ in Netherlands (9) and $61.7 \%$ of the total TB children in Canada (12), respectively. This is unlike that seen in Kampala (13), as well as in Australia (10) and in the western world (14), where pediatric tuberculosis is largely a disease of infants and young children, with a higher proportionate TB notification in 0 to 4 year-age than the other age groups.

The distribution of primary sites of infection reported in literature showed that the proportion of PTB among all childhood TB cases was predominant, ranging from 60 to $80 \%(10,13,15)$. Previous studies in North America revealed that PTB represented $72-80 \%$ of all TB load, and that lymphadenitis was the most extra-pulmonary involved site $16.7 \%-$ $21.4 \%$, followed by bone and joints $0.9 \%-1 \%$, central nervous system $0 \%-3.3 \%$, and miliary TB $1.3 \%-2.8 \%(12,16)$. A prospective study conducted in India showed that $46 \%$ of children with TB had EPTB, of whom $75 \%$ had TB meningitis (17). Otherwise, in our study, the proportion of EPTB exceeded $80 \%$ among all childhood TB, among which lymph node was the most common manifestation of EPTB. This was not surprising since these findings paralleled the distribution of TB cases among adults in our country. In Tunisia, the EPTB/PTB ratio increased from 19.6\% in 1996 to 32.6\% in 2007, which was strongly associated with lymph node TB (18).

Dosing strategies for drug-sensitive TB have improved with dispersible fixed drug combinations now available (19). In our study, $28.5 \%$ of children with TB received this regimen. This could be of a paramount importance because it improved adherence to treatment and may be cost-saving for many children with TB.

The estimated overall annual TB incidence of 4.09/100 000 in our population was within overall rates published recently by the ECDC and close to those reported from other low-endemic settings (20). The average annual rate of TB reported in previous studies was 4.8 per 100000 children under 16 years of age in New-Zealand (15) and 5.37/100 000 in Greece (21). Higher rates were reported in Congo (10/100 000 population/year) (3), in Uganda (44/100 000 population in 2010) (13) and in Zambia (69-135/100 000 during 2004-2011) (22). These discrepancies might be due a high HIV coinfection rate and low anti-retroviral uptake over the review period in high-endemic countries. However, The TB burden in children in low-income countries remains undefined because TB is easily missed owing to difficulties in making an accurate diagnosis of TB in children and also owing to the problems in differentiating TB from other childhood respiratory infections, especially in children aged under five years (23). TB incidence varied widely according to age groups. In Australia, the average annual notification rates were significantly higher for those aged 0-4 years than for those aged 59 years or 10-14 years (10). In Denmark, the highest incidence rate of TB was amongst children aged 10-14 years in 2001 (11). These findings were in line with our results, suggesting the higher transmission risk of TB in school-age children compared with younger children. In this perspective, it has been demonstrated that the transmission of TB during outbreaks involving children of school-age among close contacts in school outbreaks are on average higher $(69.8 \%$ vs. $39.3 \%$ ) if the index case is a child than an adult (24).

The main results of this study showed that the epidemiological profile of childhood TB had significantly changed in our region within the last two decades. TB incidence rate had experienced a clear resurgence between 1995 and 2016. 
Similar results were reported in New-Zealand, showing an increase between 1992 and 2001 in childhood TB case notification (15) and in Congo, where a sharp rise in TB case notification number was observed from 1995 to 2014 (3). Similarly, TB case notification of children aged 0-14 years increased from 13.4/100,000 in 2011 to about 17.2/100,000 in 2014 in Nigeria (25) and up to 51/100,000 in Malawi and over 300/100,000 in South Africa (26). The observed increasing trend in our study can be explained by delays in case-finding among adults, probably related to the high detection rate and the number of infectious adults in the environment. On the other hand, the incidence of TB in Qatari children declined from 11/100 000 children population in 1983 to a plateau of 7/100 000 in 1989 through 1996 (27). Likewise, the ratio of TB case notifications in children to those in adults for all reported TB cases decreased in Denmark during the period 2000-2009 (11). This trend reflects the change in the level of recent transmission and treatment efficiency in the country. Furthermore, this upward trend suggested an improvement in TB surveillance system in recent years. In fact, TB management was integrated in primary health care structures, where first line doctors insisted on parents' education to raise awareness about the importance of TB screening and the first clinical signs of pediatric TB at an early stage.

According to anatomical site, EPTB burden has significantly risen during the study period, notably lymph node TB, while a non-significant decline in PTB was noted. EPTB has been suggested to be a more useful indicator compared with PTB in children because the diagnosis is easier. High rates of raw milk consumption and close contact with animals, markedly in rural areas in our region may argue our findings. Similarly, a study conducted in India showed an increase in the proportion of cases of EPTB over the last 5 decades, which was predominantly due to an increase in lymph node tuberculosis (28). In fact, trends TB epidemiology has radically changed since the advent of the HIV pandemic (29), which would result in the increased incidence of EPTB at the expense of the conventional pulmonary form. The diagnostic dilemma of childhood TB, weak surveillance system for reporting childhood PTB to the national tuberculosis program and the failure to carry out effective contact tracing of children who are household contacts of smear-positive PTB cases may be responsible for this finding.

Previous study reported a decrease in TB among children aged under 14 years between 2011 and 2014 (3). Similar to our results, a significant increase in TB notification in age group 0 to 4 years was reported in Congo, attributable to the increased focus by the national program on TB diagnosis in the under-fives (3). However, a significant decline in notification rate was noted in this age group in Uganda (13). Children less than 5 years old have been shown to be more susceptible to TB due to the immaturity of their immune system. This observation might be explained by the extra efforts to train health workers in childhood TB diagnosis and the emphasis on developing a pediatric TB curriculum and undertaking systematic training and mentorships for young children. Another possible explanation for this is the relatively low effectiveness of BCG vaccination in children, yielding 50\% in the reduction of the TB disease risk (30). Therefore, it is important for policy makers and public health workers to design services and to allocate resources in order to reduce the burden of TB in young children. Furthermore, the study's findings were in line with the belief that TB is a poverty-related disease and that its burden lies more within rural districts, where a rise in TB incidence was observed. Poor housing and environmental conditions, food insecurity, financial difficulties and malnutrition in rural districts may argue these upward trends. Reducing regional disparities and providing basic care in rural areas should be a health-care priority in our country.

The present study was the first to assess TB chronological trends stratified by demographic characteristics over the last two decades in Tunisia. However, it had some limitations: Firstly, because of the retrospective data collection, the patients were not followed-up during the study period and the treatment outcome as well as the response to therapy could not be assessed. Secondly, analyzing data from a delimited area may not reflect the real burden of childhood TB in the whole country. Another limitation of this study is possible missing or incomplete data, as well as potential biases and errors during date entry. Further nation-wide and prospective studies are recommended to better estimate the extent of childhood TB.

\section{CONCLUSION}

Our study provided an insight into the burden of childhood TB in South of Tunisia. A significant rise in TB incidence rate was observed among high risk groups. Therefore, implementing preventive and control strategies must be urgently prioritized, with an emphasis on contact screening, maintaining a high BCG vaccination coverage and awareness-raising activities in the community in order to reduce TB transmission in this highly vulnerable population. 


\section{REFERENCES}

1. World Health Organization. Global tuberculosis report 2017. In: Global tuberculosis report 2017.

2. Nelson LJ, Wells CD. Global epidemiology of childhood tuberculosis. Int J Tuberc Lung Dis. 2004;8(5):636-47.

3. Loukia A, Joseph SD, Zacharie K, Gertrude L, Kapay K, Patrick KK. Trends in Tuberculosis Epidemiology among Children in the Democratic Republic of Congo. J Tuberc Res. Scientific Research Publishing; 2016;04(04):235-48. https://doi.org/10.4236/jtr.2016.44026

4. World Health Organization. Implementing tuberculosis diagnostics: A policy framework. WHO [Internet].; 2016; Available from: http://www.who.int/tb/publications/implementing_TB_diagnostics/en/ Accessed 2019 Mars 27

5. NIST. National Institute of Statistics, Tunisia. General Population Census 2004. Available from: http://www.ins.tn/fr/publication/recensement-général-de-la-population-et-de-Ihabitat-de-2004-résultats-parunité. Accessed 2019 Mars 27

6. NIST. National Institute of Statistics, Tunisia. General Population Census. 2014. Available from: http://www.ins.tn/fr/publication/recensement-général-de-la-population-et-de-lhabitat-2014-vol9. Accessed 2019 Mars 27

7. Kim H -J, Fay MP, Feuer EJ MD. Permutation tests for joinpoint regression with applications to cancer rates. Stat med. 2000;19(3):335-51. https://doi.org/10.1002/(SICI)1097-0258(20000215)19:3<335::AID-SIM336>3.0.CO;2-Z

8. Winston CA, Menzies HJ. Pediatric and adolescent tuberculosis in the United States, 2008-2010. Pediatrics. NIH Public Access; 2012;130(6):e1425-32. https://doi.org/10.1542/peds.2012-1057 PMid:23184110 PMCid:PMC4602373

9. Erkens CG, de Vries G, Keizer ST, Slump E, van den Hof S. The epidemiology of childhood tuberculosis in the Netherlands: still room for prevention. BMC Infect Dis. 2014;14(1):295. https://doi.org/10.1186/1471-2334-14295 PMid:24885314 PMCid:PMC4068078

10. Teo SS, Tay EL, Douglas P, Krause VL, Graham SM. The epidemiology of tuberculosis in children in Australia, 2003-2012. Med J Aust. 2015;203(11):440. https://doi.org/10.5694/mja15.00717 PMid:26654612

11. Hatleberg $\mathrm{Cl}$, Prahl JB, Rasmussen JN, Andersen PH, Bjerrum S, Thomsen VO, et al. A review of paediatric tuberculosis in Denmark: 10-year trend, 2000-2009. Eur Respir J. 2014;43(3):863-71. https://doi.org/10.1183/09031936.00059913 PMid:23988765

12. A Population-Based Study of Tuberculosis in Children and Adolescents in Ontario. Pediatr Infect Dis J 2009; 28(5):416-9. https://doi.org/10.1097/INF.0b013e3181920d4d PMid:19352212

13. Wobudeya E, Sekadde-Kasirye M, Kimuli D, Mugabe F, Lukoye D. Trend and outcome of notified children with tuberculosis during 2011-2015 in Kampala, Uganda. BMC Public Health. 2017;17(1):963. https://doi.org/10.1186/s12889-017-4988-y PMid:29258581 PMCid:PMC5735639

14. Kimerling ME, Vaughn ES, Dunlap NE. Childhood tuberculosis in Alabama: epidemiology of disease and indicators of program effectiveness, 1983 to 1993. Pediatr Infect Dis J. 1995;14(8):678-84. https://doi.org/10.1097/00006454-199508000-00006 PMid:8532425

15. Howie S, Voss L, Baker M, Calder L, Grimwood K, Byrnes C. Tuberculosis in New Zealand, 1992-2001: a resurgence. Arch Dis Child. 2005;90(11):1157-61. https://doi.org/10.1136/adc.2004.066415 PMid:16243871 PMCid:PMC1720148

16. Pediatric tuberculosis in Alberta: Epidemiology and case characteristics (1990-2004) Can J Public Health 2007; 98(4):276-80

17. Jain SK, Ordonez A, Kinikar A, Gupte N, Thakar M, Mave V, et al. Pediatric tuberculosis in young children in India: a prospective study. Biomed Res Int. Hindawi; 2013;2013:783698. https://doi.org/10.1155/2013/783698 PMid:24386640 PMCid:PMC3872373

18. Smaoui S, Mezghanni MA, Hammami B, et al. Tuberculosis lymphadenitis in a southeastern region in Tunisia: Epidemiology, clinical features, diagnosis and treatment. Int J Mycobacteriology; 2015;4(3):196-201. https://doi.org/10.1016/j.jimyco.2015.04.004 PMid:27649866

19. Tuberculosis disease in children - UpToDate 2018; Available from: https://www.uptodate.com/contents/tuberculosis-disease-in-children. Accessed 27.03.2019

20. Sandgren A, Hollo V, Quinten C, Manissero D. Childhood tuberculosis in the European Union/European Economic Area, 2000 to 2009. Eurosurveillance. European Centre for Disease Prevention and Control; 2011;16(12):19825.

21. Syridou G, Mavrikou M, Amanatidou V, et al. Trends in the epidemiology of childhood tuberculosis in Greece. INT J TUBERC LUNG DIS. 2012;16(6):749-55. https://doi.org/10.5588/ijtld.10.0717 PMid:22507870 
22. Kapata N, Chanda-Kapata P, O'Grady J, et al. Trends in Childhood Tuberculosis in Zambia: A Situation Analysis. J Trop Pediatr. 2013;59(2):134-9. https://doi.org/10.1093/tropej/fms065 PMid:23243079

23. Kapata N, Chanda-Kapata P, O'Grady J, et al. Trends of Zambia's tuberculosis burden over the past two decades. Trop Med Int Heal. 2011;16(11):1404-9. https://doi.org/10.1111/j.1365-3156.2011.02849.x PMid:21797950

24. Roberts JR, Mason BW, Paranjothy S, Palmer SR. The Transmission of Tuberculosis in Schools Involving Children 3 to 11 Years of Age. Pediatr Infect Dis J. 2012;31(1):82-4. https://doi.org/10.1097/INF.0b013e31823378c9 PMid:21941217

25. Daniel OJ, Adejumo OA, Abdur-Razzaq HA, Ebunoluwa JO. Trend of childhood TB case notification in Lagos, Nigeria, 2011-2014. Int J Mycobacteriology; 2015;4(3):239-44. https://doi.org/10.1016/j.ijmyco.2015.05.010 PMid:27649872

26. van Rie A, Beyers N, Gie RP, Kunneke M, Zietsman L, Donald PR. Childhood tuberculosis in an urban population in South Africa: burden and risk factor. Arch Dis Child. 1999;80(5):433-7. https://doi.org/10.1136/adc.80.5.433 PMid:10208948 PMCid:PMC1717911

27. Al-Marri MR. Childhood tuberculosis in the State of Qatar: the effect of a limited expatriate screening programme on the incidence of tuberculosis. Int J Tuberc Lung Dis. 2001;5(9):831-7.

28. Mukherjee A, Lodha R, Kabra SK. Changing Trends in Childhood Tuberculosis. Indian J Pediatr. Springer-Verlag; 2011;78(3):328-33. https://doi.org/10.1007/s12098-010-0298-4 PMid:21161446

29. Burzynski J, Schluger N. The Epidemiology of Tuberculosis in the United States. Semin Respir Crit Care Med. 2008;29(05):492-8. https://doi.org/10.1055/s-0028-1085701 PMid:18810683

30. Michelsen SW, Soborg B, Koch A, et al. The effectiveness of BCG vaccination in preventing Mycobacterium tuberculosis infection and disease in Greenland. Thorax. 2014 ;69(9):851-6. https://doi.org/10.1136/thoraxjnl2014-205688 PMid:24969643

$\diamond \diamond \diamond \diamond \diamond \diamond \diamond$

http://www.ejgm.co.uk 